\title{
Effects of Dizocilpine Pretreatment on Parvalbumin Immunoreactivity and Fos Expression after Cerebral Ischemia in the Hippocampus of the Mongolian Gerbil
}

\author{
Young-Bae KWON, II-Suk YANG, Kyung-Sun KANG ${ }^{1)}$, Ho-Jae HAN ${ }^{2}$, Yong-Soon LEE ${ }^{1)}$ and Jang-Hern LEE* \\ Departments of Veterinary Physiology and ${ }^{l}$ Veterinary Public Health, College of Veterinary Medicine, Seoul National University, \\ Suwon 441-744, and ${ }^{21}$ Hormone Research Center, Chonnam National University, Kwang-ju 550-070, South Korea
}

(Received 27 September 1999/Accepted 7 October 1999)

ABSTRACT. The mechanisms of ischemic neuronal death have been focused on glutamate receptor activation and subsequent elevation of intracellular $\mathrm{Ca}^{2+}$ concentration. The purpose of this study was to evaluate the effects of dizocilpine, an NMDA receptor antagonist, pretreatment on Fos expression and parvalbumin (PV, calcium binding protein) immunoreactivity in the hippocampus of the mongolian gerbil after global ischemic insults. The number of PV-immunoreactive (PV-ir) neurons in CA1 were significantly decreased from 1 day after cerebral ischemia, while dizocilpine pretreatment completely suppressed the loss of PV-ir neurons in CA1. Dizocilpine pretreatment also protected the structural loss of microtubule-associated protein 2 immunoreactivity in CA1 after ischemic insults. In addition, dizocilpine pretreatment increased Fos expression in both hippocampal CA3 and CA4 after $3 \mathrm{hr}$ ischemic reperfusion as compared to that of the saline pretreated group. Subsequently, the Fos-defined cellular activity of PV-ir neurons was slightly increased by dizocilpine pretreatment in the hippocampal area. This study demonstrated that NMDA receptor mediated calcium influx was associated with the loss of PV-ir neurons in CA1 hippocampal region, and that dizocilpine pretreatment increased Fos expression and the neuronal activity of PVir neurons in the non-vulnerable region of hippocampus after cerebral ischemia. Based on this data, we conclude that the protective effect of dizocilpine may be induced by the regulation of calcium overload, or by the upregulation of a neuroregenerative initiator such as Fos protein.-KEY WORDS: dizocilpine, Fos, gerbil, global ischemia, parvalbumin.

Delayed neuronal cell death occurs in the hippocampal areas, especially CA1 region, within a few days after transient forebrain ischemia [20]. The mechanisms of ischemic neuronal death have been focused on glutamate receptor activation and subsequent elevation of intracellular $\mathrm{Ca}^{2+}$ concentration [11]. Numerous studies have revealed that treatment with NMDA receptor antagonist, dizocilpine, decreases neuronal cell death after cerebral ischemic insults $[13,15]$.

Calcium-binding proteins such as parvalbumin (PV) is thought to protect neurons against cytotoxic calcium overload because of their potential buffering ability [4, 19]. However, whether PV can buffer the massive calcium influx by NMDA receptor in the hippocampus after transient cerebral ischemia is controversial $[1,5]$. Therefore, further investigation is required to verify the inter-relationship between PV immunoreactivity and the activation of NMDA receptor during ischemic conditions.

The induction of the $c$-fos proto-oncogene is detected at mRNA and protein levels in resistant regions of the hippocampus after cerebral ischemia [18]. Calcium entry via the NMDA receptor is important in inducing $c$-fos mRNA expression in cultured cortical neuron [17]. In addition, pretreatment with dizocilpine largely inhibits the mRNA expression of $c$-fos in the hippocampus $4 \mathrm{hr}$ after ischemic induction, indicating that the $c$-fos induction may

\footnotetext{
* Correspondence to: Lee, J. H., Department of Veterinary Physiology, College of Veterinary Medicine, Seoul National University, Suwon 441-744, South Korea.
}

be associated with NMDA receptor activation [10]. Since the Fos expression during the post-ischemic period regulates the subsequent expression of nerve growth factor gene, Fos expression may play a functional role in neuroregeneration after cerebral ischemia [3]. Therefore, it is possible that NMDA antagonist pretreatment modify the expression of Fos protein in the hippocampus after ischemic insults.

The purpose of this study was to evaluate the effects of dizocilpine pretreatment on Fos expression and PV immunoreactivity in the hippocampus of the mongolian gerbil after global ischemic insult. We also analyzed the cellular activity of PV positive neurons after dizocilpine pretreatment and cerebral ischemic conditions using a double staining technique for Fos and PV [14]. In addition, we confirmed the degree of ischemic damage and the effect of dizocilpine using microtubule-associated protein 2 (MAP2) immunohistochemistry.

\section{MATERIALS AND METHODS}

Mongolian gerbils (Meriones ungiculatus, 8-12 week-old) were obtained from the Laboratory Animal Center of Seoul National University (SNU). All of the experimental methods used in the present study were approved by the Animal Care and Use Committee at SNU and conformed to NIH guidelines (NIH publication No. 86-23, revised 1985). Male Mongolian gerbils were anesthetized with isoflurane in $70 \%$ $\mathrm{N}_{2} \mathrm{O}$ and $30 \% \quad \mathrm{O}_{2}$ (4\% induction: $1.5 \%$ for maintenance). Forebrain ischemia was induced for $10 \mathrm{~min}$ by clipping the bilateral common carotid arteries. Rectal temperature was 
monitored and maintained at $37.5 \pm 0.5^{\circ} \mathrm{C}$ with a temperature controller (Model \#150, CMA) and overhead lamps during the ischemic period until $30 \mathrm{~min}$ after reperfusion. We confirmed the induction of cerebral ischemia by noting the reduction in the perfusion rate of the ophthalmic artery using an ophthalmic scope. Only animals showing a significant reduction of ophthalmic blood flow during ischemic induction were used in this study. The NMDA antagonist, dizocilpine $(5 \mathrm{mg} / \mathrm{kg}$ ), or vehicle (saline), was adminisered intraperitoneally $1 \mathrm{hr}$ before the ischemic insult.

The experimental animals were sacrificed at $3 \mathrm{hr}, 1$ day, 2 days, 3 days and 5 days following cerebral ischemia with deep isoflurane anesthesia, and perfused transcardially with calcium-free Tyrode's solution followed by fixative containing $4 \%$ paraformaldehyde and $0.2 \%$ picric acid in $0.1 \mathrm{M}$ phosphate buffer ( $\mathrm{pH}$ 6.9). Seventy ischemic gerbils (7 animals for every survival time after ischemia in saline pretreated group and dizocilpine pretreated group) and twenty-five sham-operated animals were used in immunohistochemical study. Frozen transverse sections of $40 \mu \mathrm{m}$ thickness were obtained and processed free floating following the avidin-biotin method (ABC) as previously described [12]. After preincubating in 3\% normal rabbit or goat serum, the sections were incubated with monoclonal mouse parvalbumin antibody (Sigma, 1:10,000), monoclonal mouse MAP2 antibody (Sigma, 1:10,000) or polyclonal rabbit Fos antibody (Calbiochem, 1:10,000) at $4^{\circ} \mathrm{C}$ overnight. Sections were incubated for $1 \mathrm{hr}$ with the appropriate biotinylated secondary antibody (Vector) at a dilution 1:200 and followed by incubation in ABC (Vector, $1: 250$ ) for $1 \mathrm{hr}$ at room temperature. Peroxidase activity was visualized with 3-3 diamino-benzidine (DAB) and hydrogen peroxidase. For double-labeling immunohistochemistry, the sections were first incubated with Fos antibody and immunoreaction was visualized with $0.2 \%$ nickel DAB. Subsequently, the sections were incubated with parvalbumin antibody and the immunoreaction was visualized with DAB as previously described [14]. For each animal, five sections at $200 \mu \mathrm{m}$ interval were bidirectionly selected at bregma $-3.14 \mathrm{~mm}$. The number of Fos and PVir neurons was counted using a computerized imaging analyzer (Metamorph, Universal Imaging Co. + Micromax Kodak 1317 Cooled CCD, Princeton Instrument Co.). Statistical analysis between groups was performed with a one way ANOVA (T-test).

\section{RESULTS}

PV-immunoreactive (PV-ir) neurons in the hippocampus of the control group were non-pyramidal neurons located in the pyramidal cell layer and stratum oriens of CA1 and CA3, and the granular cell layer of the dentate gyrus (DG). The PV-ir neurons and fibers were greatly reduced in CA1 from 1 day after ischemia onward (Fig. 1B and Fig. 2) as compared to the sham operated group (Fig. 1A and Fig. 2). Furthermore, only a few PV-ir neurons were observed in
CA1 from 3 days up to 5 days after the ischemic insult (Fig. 2). When dizocilpine was pretreated at $1 \mathrm{hr}$ before ischemic induction, the reduction of PV-ir neurons was completely suppressed as compared to that of the vehicle treated group (Fig. 1C and Fig. 2).

No significant change in MAP2 immunoreactivity was observed in the hippocampus until 2 days after ischemia. At three days after ischemia, a severe loss of MAP2 immunoreactivity was found in the hippocampal CA1 (Fig. 1E) as compared with sham control (Fig. 1D). Dizocilpine pretreatment also protected the loss of MAP2 immunoreactivity in CA1 after ischemic insult (Fig. 1F).

Fos-immunoreactive neurons in sham operated animals were not observed in whole hippocampal areas (Table 1). Dizocilpine pretreatment had no significant effect on the Fos expression of sham operated animals. At three hours after ischemic induction, highly elevated Fos expression was detected in the hippocampus compared to sham operated animals (Fig. 3A), most notably in CA3 $(20.5 \pm 3.7)$, CA4 $(30.1 \pm 7.1)$ and the dentate gyrus (DG, $80.8 \pm 5.1)$. The dizocilpine pretreatment ischemic group showed increased Fos-ir neurons in both CA3 $(45 . \pm 3.4)$ and CA4 (50.1 \pm 7.4) after $3 \mathrm{hr}$ ischemic reperfusion compared to the saline pretreated animals (Table 1 and Fig. 3B). However, Fos expression in DG was not changed by dizocilpine pretreatment after ischemia as compared to saline pretreated ischemic animals (Table 1). PV-ir neurons were also observed in CA3 and CA 4 region of hippocampus (Fig. $3 \mathrm{C})$. Double-labeling showed that approximate $10 \%$ of PVir neurons were colocalized with Fos immunoreactivity in CA3, CA4 and DG of the vehicle pretreated group (9.0 \pm 1.0 in $91.4 \pm 5.4$ of PV-ir neurons). However, dizocilpine pretreatment slightly increased the Fos-defined cellular activity of PV-ir neurons in the hippocampal area (25.1 \pm 3.5 in $90.5 \pm 6.1$ of PV-ir neurons, Fig. 3D).

\section{DISCUSSION}

PV-ir neurons, colocalized with GABA in the CA1, are resistant to ischemic episodes because multiple neurotrophic factors converge in these surviving neurons of the gerbil hippocampus $[4,19]$. We also observed that PV-ir neurons were preserved in CA3, CA4 and DG after ischemic induction (data not shown). However, the present study showed a significant decrease of PV-ir neurons observed in CA1 from 1 day after ischemic insult. Other groups also demonstrated that transient cerebral ischemia can cause a loss of PV-ir neurons in the rat $[2,8]$ and mongolian gerbil $[1,5]$. This suggests that neuronal cell death in area CA1 is caused by secondary massive calcium influx, exceeding the buffering ability of PV. Subsequently, a severe loss of MAP2 immunoreactivity was also observed in the CA1 from three days after ischemia. This indicates that the loss of PV-ir neurons precedes the structural damage of CA1 after ischemia. Therefore, it is assumed that the calcium buffering effect of PV plays a pivotal role in the cell surviving during ischemia. 

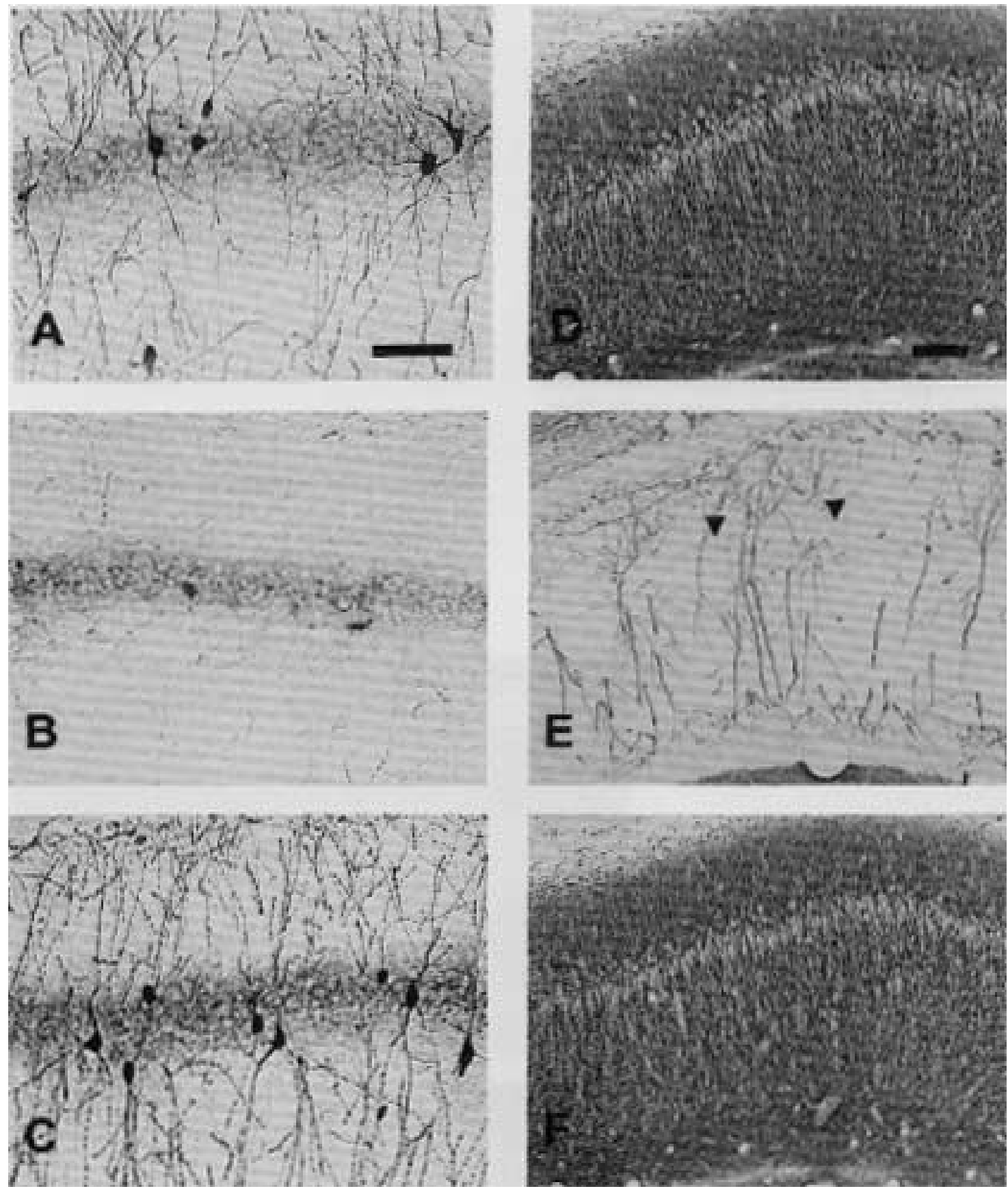

Fig. 1. Parvalbumin immunoreactivity in CA1 is significantly decreased in saline pretreated ischemic animals (Sal+Isch, B) as compared to sham operated animals (Sham, A) at 1 day after ischemia. The loss of $\mathrm{PV}$-immunoreactive (PV-ir) neurons is completely protected by dizocilpine pretreatment (C). In Sal+Isch, MAP2 immunoreactivity is decreased at 3 day after ischemia (E, arrowhead). In the dizocilpine pretreatment group (F), the loss of MAP2 immunoreactivity recovered to the level of Sham (D). Bar=200 $\mu \mathrm{m}$.

In this study, dizocilpine pretreatment completely inhibited the loss of PV- and MAP2-immunoreactivities. In a previous study, dizocilpine showed a neuroprotective effect against ischemic damage by its hypothermic action during the ischemic period $[7,13]$. However, in this study rectal temperature was maintained at $37.5 \pm 0.5^{\circ} \mathrm{C}$ from the ischemic period to $30 \mathrm{~min}$ after reperfusion. Therefore, the protective effect of dizocilpine probably has no relation to hypothermia. During ischemia, $\mathrm{Ca}^{2+}$ entry via NMDA receptors accounts for the earliest rise in cytosolic $\mathrm{Ca}^{2+}[22]$. 


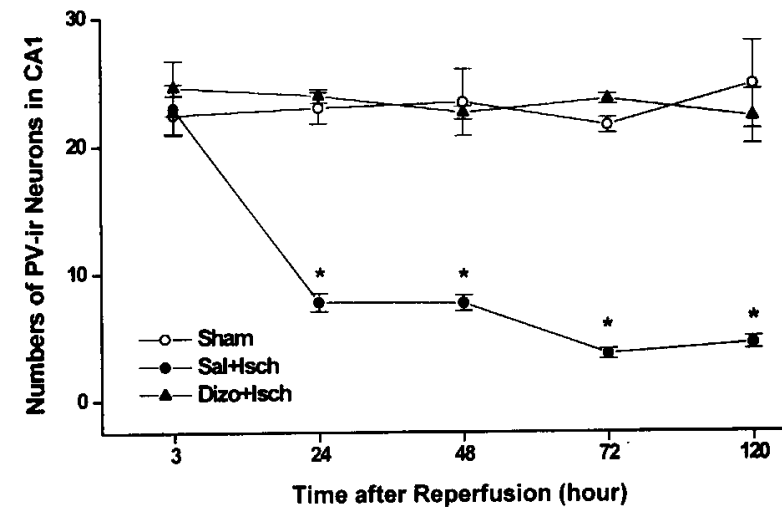

Fig. 2. The number of parvalbumin-immunoreactive (PV-ir) neurons in the CA1 area of sham control animals (Sham), saline-pretreatment $(\mathrm{Sal}+\mathrm{Isch})$ and dizocilpine-pretreatment postischemic animals (Dizo+Isch) was denoted by Mean \pm SEM. Each value was obtained by counting the number of $\mathrm{PV}$-ir neurons in five consecutive sections (at $200 \mu \mathrm{m}$ interval) of 5-7 animals $(\mathrm{n}=95)$ at every period. $* \mathrm{P}<0.01$ : significantly different from Sham group.
Table 1. The effect of dizocilpine (Dizo, $5 \mathrm{mg} / \mathrm{kg}$ ) pretreatment on the Fos expression at $3 \mathrm{hr}$ after ischemic insult in the hippocampal area of mongolian gerbil

\begin{tabular}{cccc}
\hline Group & CA3 & CA4 & DG \\
\hline Sham control & $1.8 \pm 0.2$ & $1.1 \pm 0.5$ & $1.3 \pm 0.3$ \\
Saline + Ischemia & $20.5 \pm 3.7^{*}$ & $30.1 \pm 5.1^{*}$ & $80.8 \pm 5.1^{*}$ \\
Dizo + Ischemia & $45.2 \pm 3.4^{*+}$ & $50.1 \pm 4.4^{*+}$ & $84.5 \pm 8.2^{*}$ \\
\hline
\end{tabular}

a) Number of Fos-immunoreactive neurons (Mean \pm SEM) was obtained by counting from a $500 \mu \mathrm{m}$ segment long of CA3, CA4 and dentate gyrus (DG) in the five consecutive sections of 5-7 animals using a computerized imaging analyzer.

b) $* \mathrm{P}<0.05$ : significantly different from Sham control.

c) ${ }^{+} \mathrm{P}<0.05$ : significant difference between saline-pretreated ischemic group and dizocilpine-pretreated ischemic group.

The early calcium influx in cerebral ischemia is responsible for delaying neuronal cell death by alteration of numerous enzyme activities, including phopholipases, endonucleases and proteases [11]. In addition, the protective effect of dizocilpine is achieved only by pretreatment, not by posttreatment [13]. Therefore, the neuroprotective effect of

Fig. 3. Fos expression in the hippocampus of saline pretreated ischemic group (A) and dizocilpine $(5 \mathrm{mg} / \mathrm{kg})$ pretreatment group (B) at $3 \mathrm{hr}$ after ischemic insult. Bar $=400$ $\mu \mathrm{m}$. Parvalbumin-immunoreactive neurons in $\mathrm{CA} 3$ and $\mathrm{CA} 4$ regions (C). The colocalization between Fos and PV immunoreactive neurons in CA3 and CA4 regions in the dizocilpine pretreated group (D, arrowhead). Bar $=100 \mu \mathrm{m}$.

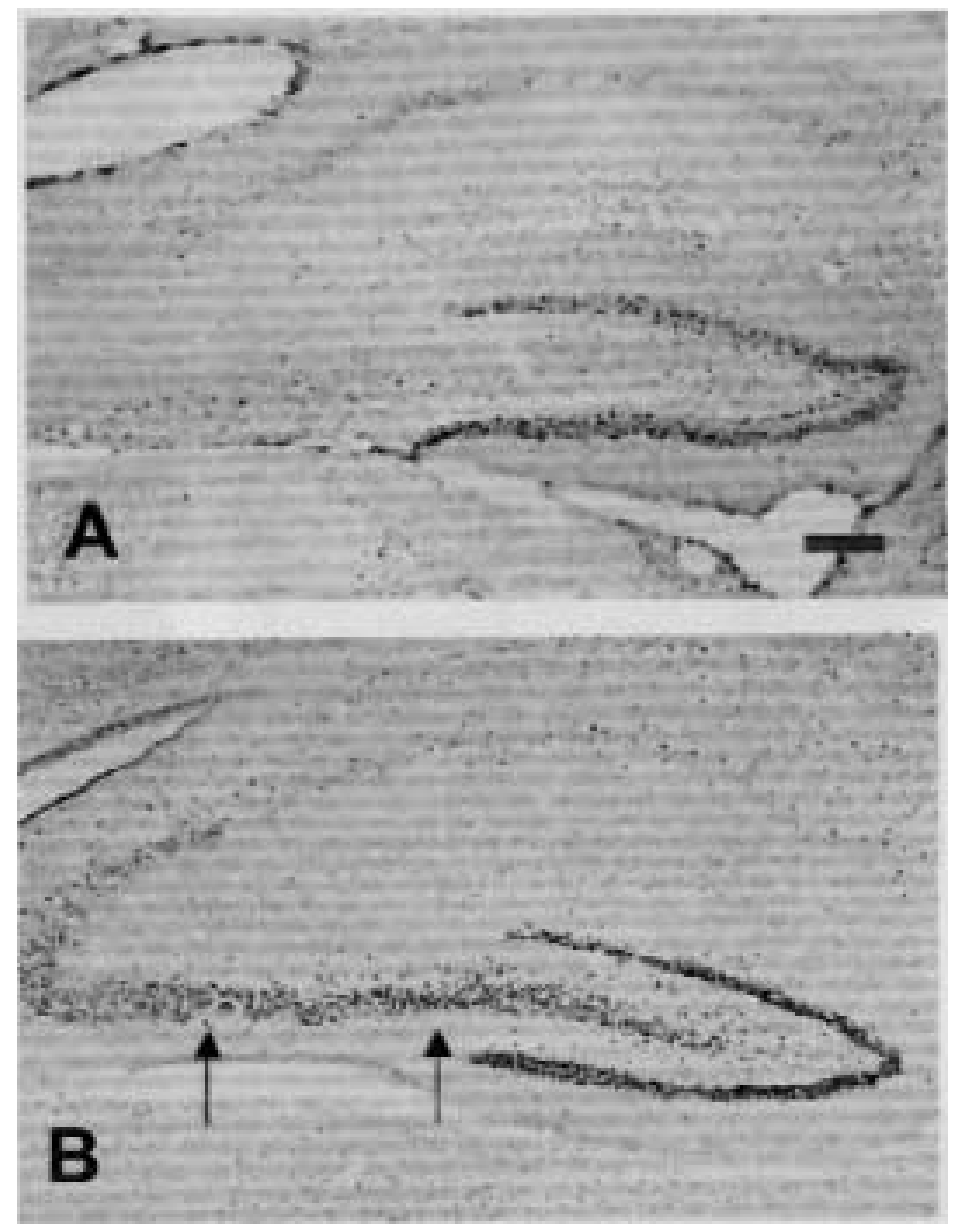


dizocilpine pretreatment is probably induced by inhibition of the early calcium influx. In further support of our hypothesis, pretreatment with L-type $\mathrm{Ca}^{2+}$ channel blocker also prevents the ischemia-induced loss of PVimmunoreactivity in CA1 [2], suggesting that inhibition of the early calcium influx may be associated with preserving PV-ir neurons.

After ischemic conditions, a transient induction of $c$-fos mRNA has been reported in both non-vulnerable regions (CA3, CA4 and DG) and the vulnerable CA1 region [9]. Fos expression in the ischemic group of this study was increased only in the resistant regions. The failure of $c$-fos mRNA translation into protein in CA1 most likely reflects sustained postischemic protein synthesis depression including neurotrophic factors [4]. Furthermore, the DNAbinding activity of AP1 is persistently potentiated in the resistant CA3 subfield and dentate gyrus, but not in CA1, after forebrain ischemia [21]. The increase of AP1 binding activity and the expression of Fos may be associate with surviving neuronal cells in the non-vulnerable region against ischemic injuries.

Kinouchi and his colleagues reported that dizocilpine pretreatment partially attenuates the increase of $c$-fos mRNA in the hippocampus at $4 \mathrm{hr}$ after ischemic insult [10]. The present study also demonstrated that CA1 pyramidal neurons, which are the most vulnerable to ischemia, did not express Fos in response to dizocilpine pretreatment. However, dizocilpine pretreatment significantly increased ischemia-induced Fos expression in the non-vulnerable regions, especially $\mathrm{CA} 3$ and $\mathrm{CA} 4$, comparing with vehicle treatment ischemic animals. Previous studies demonstrate that the calcium concentration in the CA1 is higher in the early stage of ischemia than that in the CA3 and DG, and that this early calcium influx is inhibited by dizocilpine pretreatment [15]. The expression of Fos protein is followed by the expression of the late effector genes, such as the various neurotrophin genes [16]. Furthermore, the expression of neurotrophin genes (i.e. nerve growth factor and brain derived neurotrophic factor) may be important in regenerative processes and functional recovery after cerebral ischemia [6]. Therefore, we assume that the increase of Fos expression in the CA3 and CA4 may reflect the molecular mechanism mediating the neuroprotective effect of dizocilpine in the early reperfusion period. In addition, the

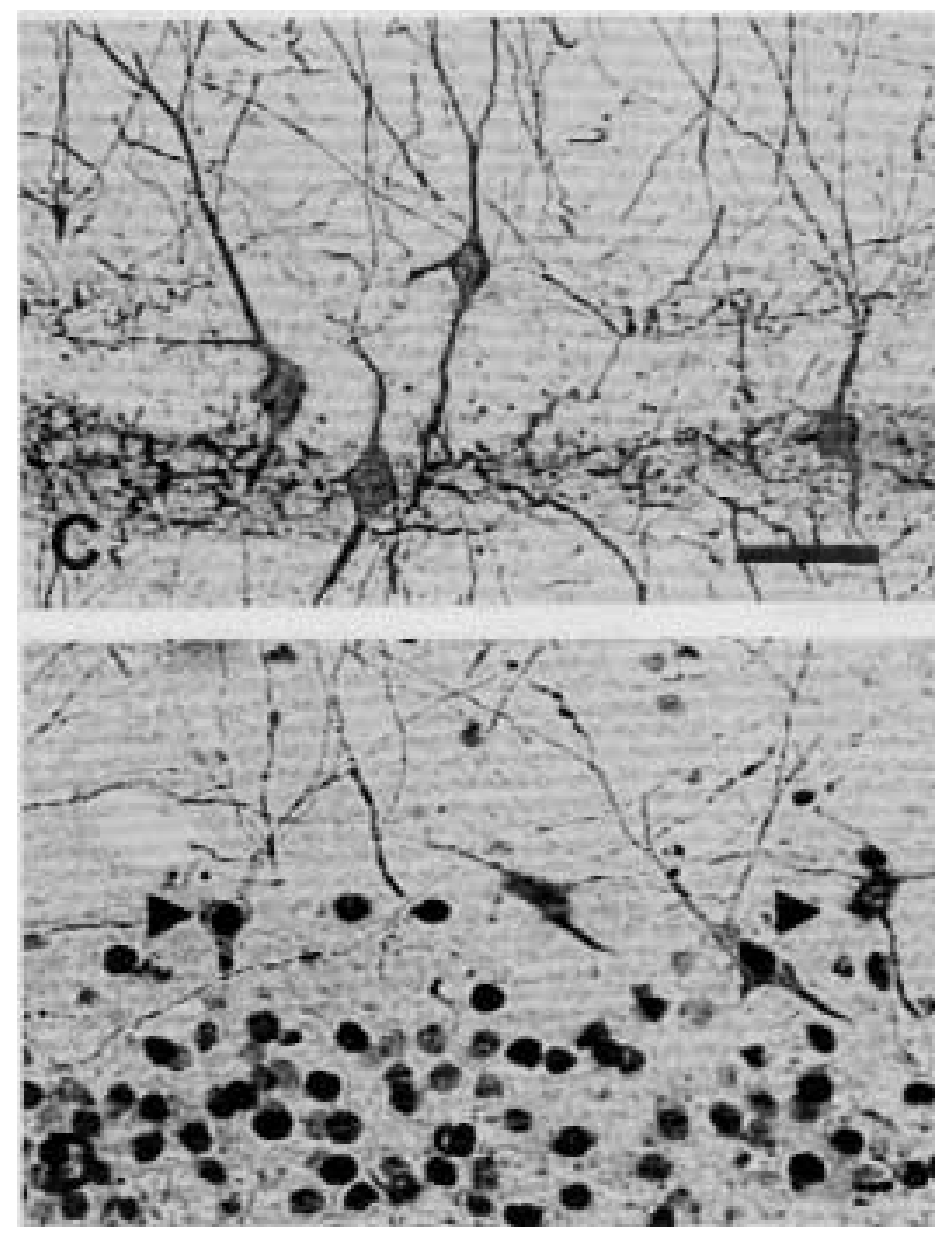


neuronal activity of PV-ir neurons was slightly increased by the dizocilpine pretreatment in non-vulnerable region after cerebral ischemia, which may reflect the neuroprotective effect of dizocilpine in the early reperfusion period.

This study demonstrated that NMDA receptor-mediated calcium influx correlates with the loss of PV-ir neurons in the CA1 hippocampal region, and that dizocilpine pretreatment increased the neuronal activity of PV-ir neurons and Fos expression in the non-vulnerable region of hippocampus after cerebral ischemia. Based on this data, the protective effect of dizocilpine may be a result of the regulation of calcium overload, or the upregulation of neuroregenerative components such as Fos protein.

ACKNOWLEDGEMENTS. This study was supported by a grant (\#HMP-96-M-4-0039) of the '96 Good Health R\&D Project, Ministry of Health and Welfare, R.O.K. The publication of this manuscript was also supported by research funds from the Research Institute for Veterinary Science (RIVS) of the College of Veterinary Medicine, Seoul National University.

\section{REFERENCES}

1. Araki, T., Kato, H., Liu, K.X., Kogure, H., Kato, K. and Itoyama, Y. 1994. An immuno-histochemical study of parvalbumin containing interneurons in the gerbil hippocampus after cerebral ischemia. Metab. Brain Dis. 9: 225-234.

2. Benyo, Z., De Jong, G.I. and Luiten, P.G. 1995. Nimodipine prevents early loss of hippocampal CA1 parvalbumin immunoreactivity after focal cerebral ischemia in the rat. Brain Res. Bulletin. 36: 569-572.

3. Cui, J.K., Hsu, C.Y. and Liu, P.K. 1999. Suppression of postischemic hippocampal nerve growth factor expression by a c-fos antisense oligodeoxynucleotide. J. Neurosci. 19: 13351344.

4. Ferrer, I., Lopez, E., Pozas, E., Ballabriga, J. and Marti, E. 1998. Multiple neurotrophic signals converge in surviving CA1 neurons of the gerbil hippocampus following transient forebrain ischemia. J. Comp. Neurol. 394: 416-430.

5. Fukuda, T., Nakano, S., Yoshiya, I. and Hashimoto, P.H. 1993. Persistent degenerative state of non-pyramidal neurons in the CA1 region of the gerbil hippocampus following transient forebrain ischemia. Neuroscience 53: 23-38.

6. Ghosh, A., Carnahan, J. and Greenberg, M.E. 1994. Requirement for BDNF in activity-dependent survival of cortical neurons. Science 263: 1681-1623.

7. Hayward, N.J., McKnight, A.T. and Woodruff, G.N. 1993. Brain temperature and the neuro-protective action of enadoline and dizocilpine in the gerbil model of global ischaemia. Eur. J. Pharmacol. 236: 247-253.

8. Johansen, F.F., Tonder, N., Zimmer, J., Baimbridge, K.G. and Diemer, N.H. 1990. Short-term changes of parvalbumin and calbindin immunoreactivity in the rat hippocampus following cerebral ischemia. Neurosci. Lett. 120: 171-714.
9. Kiessling, M., Stumm, G., Xie, Y., Herdegen, T., Aguzzi, A., Bravo, R. and Gass, P. 1993. Differential transcription and translation of immediate early genes in the gerbil hippocampus after transient global ischemia. J. Cereb. Blood Flow Metab. 13: 914-924.

10. Kinouchi, H., Sharp, F.R., Chan, P.H., Mikawa, S., Kamii, H., Arai, S. and Yoshimoto, T. 1994. MK-801 inhibits the induction of immediate early genes in cerebral cortex, thalamus, and hippocampus, but not in substantia nigra following middle cerebral artery occlusion. Neurosci. Lett. 179: 111114.

11. Kristian, T. and Siesjo, B.K. 1998. Calcium in ischemic cell death. Stroke 29: 705-718.

12. Lee, J.H. and Beitz, A.J. 1993. The distribution of brain-stem and spinal cord nuclei associated with different frequencies of electroacupuncture analgesia. Pain 52: 11-28.

13. Murase, K., Kato, H. and Kogure, K. 1993. Limited but evident protective effects of MK-801 and pentobarbital on neuronal damage following forebrain ischemia in the gerbil under normothermic conditions. Neurosci. Lett. 149: 229232.

14. Mihaly, A., M. Szente, Z., Dubravcsik, B., Boda, E., Kiraly, T., Nagy and A. Domonkos, 1997. Parvalbumin- and calbindin-containing neurons express $c$-fos protein in primary and secondary (mirror) epileptic foci of the rat neocortex. Brain Res. 761: 135-145.

15. Nakamura, K., Hatakeyama, T., Furuta, S. and Sakaki, S. 1993. The role of early $\mathrm{Ca}^{2+}$ influx in the pathogenesis of delayed neuronal death after brief forebrain ischemia in gerbils. Brain Res. 613: 181-192.

16. Sharp, F.R. 1994. The sense of antisense fos oligonucleotides. Ann. Neurol. 36: 566-577.

17. Sharp, F.R. and Sagar, S.M. 1994. Alterations in gene expression as an index of neuronal injury: heat shock and the immediate early gene response. Neurotoxicology 15: 51-59.

18. Takemoto, O., Tomimoto, H. and Yanagihara, T. 1995. Induction of $c$-fos and $c$-jun gene products and heat shock protein after brief and prolonged cerebral ischemia in gerbils. Stroke 26: $1639-1648$.

19. Tortosa, A. and Ferrer, I. 1993. Parvalbumin immunoreactivity in the hippocampus of the gerbil after transient forebrain ischaemia: a qualitative and quantitative sequential study. Neuroscience 55 : $33-43$.

20. Won, M.H., Lee, J.C., Kim, Y.H., Song, D.K., Suh, H.W., Oh, Y.S., Kim, J.H., Shin, T.K., Lee, Y.J. and Wie, M.B. 1998. Postischemic hypothermia induced by eugenol protects hippocampal neurons from global ischemia in gerbils. Neurosci. Lett. 254: 101-104.

21. Yoneda, Y., Kuramoto, N., Azuma, Y., Inoue, K., Ogita, K., Mitani, Yanase, A.H., Masuda, S., Zhang, L. and Kataoka, K. 1998. Prolongation by bifemelane of potentiation of AP1 DNA binding in hippocampal CA1 subfield of gerbils with transient forebrain ischemia. J. Neurosci. Res. 51: 574-582.

22. Zhang, Y. and Lipton, P. 1999. Cytosolic $\mathrm{Ca}^{2+}$ changes during In vitro ischemia in rat hippocampal slices: major roles for glutamate and $\mathrm{Na}^{+}$-dependent $\mathrm{Ca}^{2+}$ release from mitochondria. J. Neurosci. 19: 3307-3315. 